La configuración de Rosario en clave empresarial

\title{
Transformaciones urbanas durante las gestiones socialistas
}

Florencia Agustina Brizuela Licenciada en Ciencia Política (UNR) Maestranda en Estudios Urbanos (UNGS) Miembro Programa de Estudios Sobre Gubernamentalidad y Estado - PEGUES (UNR) Email: florencia.agustina.brizuela@hotmail.com 
Resumen

El presente artículo expone los principales hallazgos de la Tesina de Grado desarrollada para la obtención de la Licenciatura en Ciencia Política de la Universidad Nacional de Rosario, la cual se propuso indagar la forma de gobernar el espacio urbano rosarino que desplegaron las sucesivas gestiones socialistas durante las dos últimas décadas. Para ello se analizaron las racionalidades políticas que atravesaron las políticas urbanas implementadas desde 1995 a la actualidad, se rastrearon las condiciones sociales, políticas y económicas que hicieron posible su desarrollo, se describieron las tecnologías de gobierno, los planes, programas e intervenciones municipales que le dieron forma a la ciudad, y se estudiaron los efectos derivados de la modalidad de gobierno urbano que siguió Rosario.

\section{Palabras clave}

Gobierno urbano - racionalidades políticas - tecnologías de gobierno
Abstract

This paper presents the main findings of the graduation work developed for obtaining a degree in Political Science at the National University of Rosario. The thesis was aimed to investigate the way that successive socialist efforts deployed over the past two decades to govern the urban space from Rosario. For that reason, we analyzed the political rationalities that urban policies implemented from 1995 to the present experienced; we tracked the social, political and economic conditions that contributed with the development, we described the government technologies, the plans, programs and municipal interventions that shaped the city and we studied the effects derived from the urban government modality that Rosario followed.

Key words

Urban government political rationalities government technologies 


\section{Introducción}

A partir de la década del 90 comenzaron a gestarse en Rosario cambios notorios en la estructuración del espacio urbano. Con el fin de adecuar este último a las nuevas exigencias de la economía, las diversas gestiones socialistas impulsaron una serie de reformas institucionales e intervenciones urbanas que permitieron posicionar a la ciudad como el primer centro agroindustrial del país y como un importante proveedor de servicios.

Entre ellas se destacan grandes obras de infraestructura implementadas junto al gobierno nacional y provincial, como el Puente Rosario-Victoria, la autopista Rosario-Córdoba, y un conjunto de intervenciones municipales de corte turístico-cultural articuladas con el sector privado, como la Marca Rosario y la urbanización de la ribera.

Estas obras e intervenciones urbanas constituyeron a la ciudad, a partir de 2003, en un importante polo de atracción de inversiones provenientes tanto del excedente de los agro-negocios de las zonas linderas (orientadas principalmente a la construcción de inmuebles), como de grandes firmas comerciales.

En este escenario, la Tesina se propuso como objetivo general indagar la forma de gobernar el espacio urbano rosarino que desplegaron las sucesivas gestiones socialistas durante las dos últimas décadas ${ }^{1}$. Para ello se establecieron cuatro objetivos específicos: 1) analizar las racionalidades políticas que atravesaron las políticas urbanas implementadas desde 1995 a la actualidad; 2) rastrear las condiciones sociales, políticas y económicas que hicieron posible su desarrollo; 3) describir las tecnologías de gobierno, los planes, programas e intervenciones municipales que le dieron forma a la ciudad; 4) estudiar los efectos derivados de la modalidad de gobierno urbano que siguió Rosario

1 El Partido Socialista asumió la gestión municipal con Hermes Binner durante los años 1995 a 2003, a éste le siguió en la Intendencia Miguel Lifschitz (período 2003-2007 y 2007-2011) y luego Mónica Fein, actual intendenta a partir del año 2011. 
La primera hipótesis que guió el estudio postula que las gestiones socialistas a partir de 1995 asumen una modalidad empresarial de gobernar la ciudad consolidándola como una ciudad-empresa. La segunda hipótesis plantea que los efectos que se derivan de ese patrón empresarial de gobierno son la fragmentación y segregación urbana de los sectores sociales de menores ingresos.

Orientada por los mencionados objetivos e hipótesis, la investigación se apoyó en los estudios sobre gubernamentalidad desarrollados fundamentalmente en el mundo anglosajón desde los años 90. Los governmentality studies analizan las prácticas de gobierno mediante los cuales el poder efectivamente se ejerce.

Como grilla de análisis, el estudio de la gubernamentalidad se enfoca simultáneamente hacia dos instancias, las racionalidades políticas y las tecnologías de gobierno. Por racionalidades políticas se entienden aquellos campos discursivos en los cuales el ejercicio del poder es conceptualizado tanto en relación a los fines que este debe perseguir como a las formas que debe adoptar su ejercicio. Mientras que por tecnologías de gobierno se entienden todos aquellos mecanismos prácticos, reales y locales (técnicas, aparatos, documentos y procedimientos, etc.) por medio de los cuales las distintas autoridades, en este caso estatales, pretenden guiar, normalizar, instrumentalizar las ambiciones, aspiraciones, acciones de los otros a efectos de obtener los fines que ellas consideren deseables (De Marinis, 1999).

A continuación se presentan de manera resumida los resultados obtenidos para cada uno de los objetivos planteados teniendo como ejes ordenadores las racionalidades políticas y las tecnologías de gobierno que guiaron el estudio del gobierno urbano en Rosario.

\section{Racionalidades Políticas. Pensar la ciudad empresa}

En los últimos años, una serie de pensadores latinoamericanos ha analizado la manera en que la reestructuración del capitalismo a nivel mundial y las reformas institucionales y macroeconómicas en América Latina han producido cambios profundos no sólo en la con- 
figuración del territorio, sino también en las políticas urbanas, en la planificación y en las concepciones sobre la ciudad (De Mattos, 2006; Cuenya, 2000; Clichevsky, 1996). Las ciudades comienzan a ser pensadas y configuradas bajo una matriz empresarial que las instaura como agentes económicos actuando en el contexto de un mercado y encontrando en éste la regla o el modelo de planeamiento y ejecución de sus acciones.

¿En qué consiste el nuevo estilo empresarial de gobernanza urbana? El empresarialismo es, según Cuenya y Corral (2011), una forma de regulación política y social que ha reflejado y acompañado, en las últimas décadas, los procesos de reestructuración de las economías capitalistas. Para Harvey (2007), el "nuevo paradigma empresarial" que adopta el sector público en la gobernanza urbana, expresa el consenso general surgido en el mundo capitalista avanzado, durante las décadas de 1970 y 1980, de que para las ciudades es ventajoso adoptar una actitud empresarial respecto al desarrollo económico. Por su parte, Theodore, Peck y Brenner (2009) sostienen que las propuestas que comparte el enfoque empresarial (el marketing territorial, el impulso a las asociatividades público-privadas y las nuevas formas de promoción local) se erigen como un conjunto de políticas neoliberales cuya última meta es movilizar espacios de la ciudad tanto para el crecimiento económico orientado al mercado, como para las prácticas de consumo de las élites, asegurando al mismo tiempo el orden y control de las poblaciones "excluidas".

Tres principios básicos definen conceptualmente el empresarialismo urbano según Harvey (2007). En primer lugar, el nuevo empresarialismo tiene como elemento central la alianza entre sector público y sector privado, en la cual el gobierno local es uno más de los múltiples agentes que intervienen en la escena urbana. La combinación de recursos privados con capacidades gubernamentales sirve para intentar atraer fuentes de financiación externas, nuevas inversiones directas o nuevas fuentes de empleo.

En segundo lugar, la actividad de la alianza sector público-sector privado se orienta por una lógica empresarial, es decir, es de sujeción y diseño especulativos y, por lo tanto, está ligada a los peligros adjun- 
tos al desarrollo especulativo (en contraste con el desarrollo racionalmente planeado).

En tercer lugar, el empresarialismo se centra mucho más en la economía política del lugar y no en la del territorio. La construcción del lugar o la mejora de las condiciones dentro de un lugar es entendida como el impulso a proyectos específicos locales, esto es, "si bien la construcción del lugar puede tener efectos a escala metropolitana (mejora en la base impositiva, circulación local de ingresos y creación de empleos) usualmente no aborda los problemas más amplios que aquejan a la región o al territorio en su totalidad" (Cuenya y Corral, 2011:27).

La gobernanza urbana empresarial también es abordada por la Organización para la Cooperación y Desarrollo Económicos (2007). Según la OCDE, el empresarialismo urbano tiene ciertas características inconfundibles. La primera es que se propone fomentar y estimular el desarrollo económico local, adoptando la forma de "planificación positiva", que trata de generar crecimiento económico por medios proactivos, a diferencia de la "planificación pasiva" tradicional que se ocupa más de la administración del uso de suelo. La segunda característica es que se propone hacer un uso pleno de los mecanismos del mercado para alcanzar metas públicas con menos intervención pública. La tercera es que el empresarialismo urbano implica un cambio fundamental en la relación con el sector privado: se constituyen alianzas estratégicas que proporcionan la colaboración pública-privada, marco institucional indispensable para que las ciudades compitan en el mercado global combinando recursos privados y conocimientos especializados con capacidades gubernamentales locales. Por último, la planificación de políticas urbanas, bajo el enfoque empresarial, muestra características que otrora distinguieron a las empresas privadas, como la asunción de riesgos, la inventiva, el afán promocional o el lucro y la planificación estratégica. 


\section{Condiciones históricas de emergencia del enfoque empresarial en Rosario}

En el caso de Rosario, el desembarco del empresarialismo urbano se produjo a mediados de la década del noventa en un clima de grave crisis económico-financiera, de desconfianza hacia las formas tradicionales de representación y de un aumento progresivo de la protesta social. Garantizar la gobernabilidad urbana se erigió como condición necesaria para el libre funcionamiento del mercado demandado por el enfoque empresarial.

En este marco, el Partido Socialista bajo el mandato de Hermes Binner impulsó a partir de 1996 la reforma del aparato administrativo Municipal, siguiendo recomendaciones de organismos internacionales como el Banco Mundial y el CLAD quienes sostenían la necesidad de fortalecer e innovar las instituciones públicas mediante reformas institucionales que brindasen mayor eficacia, eficiencia y transparencia a los poderes públicos (Borzese, Gianatelli y Ruiz, 2006).

Los pilares de la Reforma del Estado local fueron el Programa de Descentralización ${ }^{2}$ y Modernización ${ }^{3}$ de la Municipalidad de Rosario y luego el Presupuesto Participativo Rosario ${ }^{4}$ ¿Cómo contribuye-

2 El proyecto de descentralización de la Municipalidad de Rosario comenzó a implementarse en enero de 1996. Tuvo como principal motivación mejorar la calidad de los servicios en términos de eficiencia, eficacia y agilidad, acercando la administracióna lxs ciudadanxs (Bifarello, 2005; Ghirardi, 2000). Para ello dispuso tres niveles de descentralización: la descentralización administrativa, que se desarrolló con la delimitación de seis distritos y la implementación de un Centro Municipal en cada uno de ellos; la descentralización operativa, que se concretó mediante la creación de Áreas de Servicios Urbanos encargadas del mantenimiento urbano a escala pequeña y mediana; y la descentralización política, implementada a partir de prácticas participativas como el Presupuesto Participativo.

3 El proyecto de modernización municipal también incorporó como conceptos rectores la calidad y eficiencia en la provisión de servicios y bienes a clientes externos (vecinos) o internos (personal de la municipalidad). Así a principios de 1999, se formalizó el llamado proceso de Mejora Continua para los Centro Municipales de Distrito (Bifarello, 2005), el cual se propuso estandarizar acciones mediante la documentación de todos los trámites y procedimientos administrativos y la disposición de una base de datos unificada, referenciada y conocida por todos los involucrados con la cual contar para realizar las auditorías y controles internos y externos y, de esa forma, garantizar la transparencia y mejorar las acciones de gobierno.

4 En cuanto al desarrollo de nuevos instrumentos participativos, la gestión entendía que estos servirían para impulsar "los valores de la solidaridad y la cooperación; para que lxs ciudadanxs puedan ser protagonistas del destino de su ciudad; para aumentar la responsabilidad social pública; para favorecer mecanismos de control de los actos de gobierno; para mejorar la gobernabilidad del territorio" (Bifarello, 2005:105). Para ello impulsó desde 2002 (en plena crisis social y política) la implementación del Presupuesto Participativo Rosario (PPR) que establece que lxs ciudadanxs, por distritos, disponen de un porcentaje de los recursos de inversión municipales para ser distribuidos y aplicados a proyectos y programas decididos por ellxs de manera "libre". 
ron estos proyectos al logro de la gobernabilidad? Según Campana (2012), la estrategia descentralizadora y modernizadora al proponerse aumentar la eficiencia, transparencia, capacidad y responsabilidad de las instituciones y mecanismos gubernamentales, se presentó como vía de restauración de la confianza hacia las instituciones políticas, necesaria en un contexto de deslegitimación de la política y los políticos.

Por su parte los esquemas de participación social funcionaron como tecnologías de agencia, buscando mejorar las capacidades de participación, acuerdo y acción de los individuos, y principalmente contribuyendo a neutralizar la conflictividad social post 2001. El Presupuesto Participativo Rosario fue paradigmático en este sentido ya que: "Las asambleas de vecinos, nacidas al calor del descontento y del desencanto con respecto a las instituciones, se fueron diluyendo al tiempo que se promovía el PPR. Este mecanismo se presentó como una respuesta a la demanda de participación de lxs ciudadanxs y logró posicionarse como uno de los espacios de concertación más reconocidos. Pero no fue una estrategia ingenua: hay un marco normativo, hay unas maneras de debatir, hay unos temas abiertos a discusión, hay una porción del presupuesto a considerar, en fin, hay procedimientos y técnicas específicamente dirigidas a encauzar la conducta de los participantes" (Campana, 2012:72).

Por lo tanto, al neutralizar el conflicto social y restituir la confianza hacia las instituciones públicas, las estrategias descentralizadora, modernizadora y participativa, garantizaron la estabilidad socio-política, y el consenso necesario para el funcionamiento del modelo económico y urbano empresarial que se estaba gestando. Sin embargo, su viabilidad demandaría una transformación más profunda en las funciones que hasta el momento ejercía el Municipio. Lograr un rol más activo en la economía se impuso entonces como un requisito indispensable para fomentar y estimular el desarrollo económico local. 


\section{Traducciones locales de la gobernanza urbana empresarial}

\subsection{El papel promotor del gobierno local}

El papel promotor que asumió el gobierno municipal en materia económica se sustentó en los enfoques del desarrollo local y de la planificación estratégica. Estos enfoques constituyeron la traducción ${ }^{5}$ local del empresarialismo urbano en Rosario.

Según García Delgado (1998), el rol pasivo respecto de la economía en la tradición municipalista argentina tuvo dos motivos: primero, el carácter autárquico y delegativo del gobierno local, su falta de competencias y de recursos extractivos; y segundo, el predominio de las políticas centralistas de desarrollo desde los ' 40 en adelante, donde los enfoques keynesianos y desarrollistas privilegiaron lo social y el Estado nacional. El desarrollo, si dependía de alguien, era de éste último y, como efecto, de las políticas macro.

Esta perspectiva fue cuestionada por el influjo de las privatizaciones, la descentralización y la rápida desestructuración del modelo productivo anterior. Debido a las oportunidades que generaba la economía orientada a la exportación, las dificultades de orden económico y las crecientes demandas sociales provocadas por las políticas neoliberales, los municipios se orientaron hacia un mayor activismo económico (García Delgado, 1998).

Las estrategias que escogieron los gobiernos municipales argentinos implicaron el diseño e implementación de iniciativas de desarrollo local y planificación estratégica (Catenazzi y Resse, 2000). La elección de estos enfoques no fue por azar, sino resultado del patrocinio de las entidades multilaterales de crédito y de la difusión, en América

5 El "nuevo paradigma empresarial", que adopta el sector público en la gobernanza urbana durante las décadas de 1970 y 1980 en el mundo capitalista avanzado no desembarca en la geografía latinoamericana, ni en Rosario específicamente, en su forma "pura". Por el contrario, atraviesa procesos de traducción, de resignificación en función de las regulaciones, las prácticas institucionalizadas y las disputas y los acuerdos políticos establecidos con anterioridad a su arribo. En este sentido, sostiene Mrejen “...debe evitarse pensar en meras "aplicaciones” de esquemas o tecnologías programados por una racionalidad de gobierno para pensar en procesos en los cuales, si bien hay un "original" que es traducido, esta traducción tiene lugar en espacios habitados por otros discursos y estrategias" (2013:75). 
Latina, de gestiones de corte estratégico “exitosas” en ciudades europeas como Lyon, Barcelona y Bilbao.

El enfoque del desarrollo local sostiene que en un nuevo entorno de actuación caracterizado por una creciente competencia entre países, regiones y ciudades por atraer inversiones y clientes, las administraciones locales deben introducir reformas que optimicen sus estilos de intervención en pos de generar ventajas competitivas territoriales y de asistencia a la competitividad empresarial (Fernández et al, 1997). Son las empresas el verdadero motor del desarrollo económico, de ahí el rol articulador, potenciador, "facilitador de oportunidades", más que interventor, que debe desempeñar el gobierno municipal (García Delgado, 1998). La cooperación público-privada aparece entonces como una pieza clave del nuevo enfoque y encuentra una de sus expresiones más acabadas en el Plan Estratégico Rosario (PER).

\subsection{La planificación estratégica del desarrollo.}

El Plan Estratégico Rosario (PER)

A mediados de los años 90, la gestión socialista materializó la propuesta de desarrollo local a través de un plan estratégico y participativo de actuación. La planificación estratégica fue concebida por el PER (1998) como: a) una metodología adaptable, capaz de generar intervenciones que garanticen calidad de vida urbana, progreso económico y social; b) un mecanismo para avanzar hacia formas progresivas de gobernabilidad profundizando sustantivamente la democracia través de una colaboración real entre los actores públicos y privados; c) una forma moderna, participativa y democrática de pensar y organizar el desarrollo de una ciudad.

El PER sentó las bases de uno de los principios fundamentales del empresarialismo urbano: la articulación público-privada ${ }^{6}$. Lo hizo

6 Según Miguel Lifschitz y Mirta Levín (Secretaría de Planeamiento de la Municipalidad durante el período 2003-2011) la imposibilidad que tienen los municipios de garantizar con recursos propios las grandes transformaciones urbanas, tornan un imperativo la búsqueda de fuentes de financiamiento alternativas (http://www.urb-al3.eu/uploads/documentos/recopilatorio_Habitar_Goes.pdf). En este sentido se vuelve necesario, para estos funcionarios, la cooperación entre el sector público y el sector privado asumiendo el Estado Municipal un rol promotor e inductor de la iniciativa privada sobre el mero rol regulador (Plan Urbano, 2011). 
asegurando, por un lado, la presencia de los intereses empresariales en la definición del proyecto de ciudad que se estaba gestando y suministrando, por el otro, un marco de referencia para que las empresas pudieran orientar sus inversiones y decidir sus estrategias.

El 20 de marzo de 1995 se celebró un Convenio entre la Municipalidad de Rosario y la Fundación del Banco Municipal para construir el plan estratégico de la ciudad. Hacia octubre del mismo año se conformó la Junta Promotora del PER encargada de participar en la definición del desarrollo urbano, económico y social de la ciudad. La composición de la Junta aseguró la presencia de los intereses del mercado en el proceso de planeamiento, ya que 13 de los 25 organismos e instituciones locales que la constituyeron eran los principales actores económicos de la ciudad, entre ellos: la Asociación Empresaria de Rosario, la Sociedad Rural de Rosario, la Asociación de Industriales Metalúrgicos, la Cámara Argentina de Construcción, la Bolsa de Comercio de Rosario, Canal 3, Canal 5, la Editorial del Diario La Capital, el Ente Administrador del Puerto Rosario, la Federación Agraria Argentina, la Federación Gremial de Comercio e Industria, el Foro Regional Rosario y el Aeropuerto Internacional Rosario. La importancia que adquirieron las organizaciones empresariales en la definición del proyecto de ciudad determinó, en gran medida, la estrategia de desarrollo local adoptada.

En septiembre de 1997 concluyó la versión final del Diagnóstico e inició la etapa de formulación de programas y proyectos destinados a brindar, entre otras cosas, un marco de ordenación e impulso a las actividades económicas con base local (Stanley, 2007) y un cuadro de referencia para las inversiones y decisiones de las empresas (Lifschitz, 1998).

7

El diagnóstico sostenía que era necesario dejar atrás una ciudad de marcadas exclusiones, golpeada por la crisis y el desempleo, con un déficit de liderazgo para llevar adelante los proyectos de desarrollo local; con escasa coordinación y poca visible cooperación público- público y público-privada. Se debían generar una serie de hechos económicos, sociales y políticos, que dieran un renovado impulso a la ciudad. Entre ellos: revalorizar los talentos creativos para ponerlos al servicio de la transformación; aprovechar el frente fluvial; aprovechar la ventaja comparativa derivada de la posición estratégica de la ciudad para convertirla en centro polimodal de intercambio de mercaderías y de servicios logísticos especializados; y promover la vinculación del sistema educativo con los nuevos desafíos del mundo del trabajo; etc. (PER, 1998). 
Los programas conformaron una estrategia orientada a consolidar a Rosario como centro geopolítico y económico de una amplia región metropolitana y central, y como "puerta y puerto del Mercosur" (PER, 1998:109). Se buscaba explotar las ventajas provenientes de la producción de mercancías que ofrecía el Área del Gran Rosario ${ }^{8}$ en los rubros de lácteos, cereales, oleaginosas, ganadería y frutihortícola y aprovechar las ventajas de la ubicación geoestratégica de la ciudad en el principal corredor productivo de la Argentina y el recientemente creado Mercosur. Con tal propósito se priorizó una serie de proyectos de infraestructura e institucionales.

Los proyectos institucionales considerados estratégicos buscaban consolidar a la ciudad como cabecera del Área Metropolitana del Gran Rosario (AMR). El valor de esta área se relaciona con que ella representaba el $50 \%$ del producto bruto provincial y entre el 4.5 y 5\% del PBI de la República Argentina (PER, 1998). Por lo tanto, era prioritario coordinar las actuaciones de los distintos ámbitos de la administración que operan sobre el territorio del Gran Rosario (Nación, Provincias, Municipios y Comunas), así como articular con los demás actores privados e institucionales. La creación de un Ente de Coordinación Metropolitana y de la Agencia Regional de Desarrollo ayudaría a concretar estos objetivos.

Con las obras de infraestructura, por otro lado, se apuntaba a insertar a la ciudad como centro polimodal de transporte e intercambio de la región centro del país (Córdoba, Santa Fe y Entre Ríos) y como comunidad logística del Mercosur. La Autopista Rosario- Córdoba, el Puente Rosario-Victoria, la Reconversión del Puerto de Rosario, el Sistema de gestión del sistema vial metropolitano y de accesos a la ciudad, y la Hidrovía Paraguay-Paraná, serían el andamiaje de la nueva plataforma competitiva de la región.

A estos programas se sumaron otros no estratégicos pero igualmente determinantes del perfil de servicios que adquirió la ciudad a partir del 2003. Los programas contemplaban el apoyo a Pymes loca-

8 El conjunto de comunas y municipios que conforman el AGR son: Capitán Bermúdez, Fray Luis Beltrán, Funes, Granadero Baigorria, Pérez, Puerto San Martín, Rosario, San Lorenzo y Villa Gobernador Gálvez. 
les especializadas en la rama alimenticia y metalmecánica ("PyMEs en marcha"; "Centro de la producción de alimentos"), la potenciación de las actividades turísticas ("Sistema de gestión turística de la ciudad"; "Disfrutar y cuidar del río"), la promoción de la arquitectura, la oferta cultural y el desarrollo tecnológico ("Rosario en la geografía de la creatividad"; "Impulsando la industria cultural"; "Polo de tecnología e innovación”) y la gestión de una imagen territorial de marca ("Gestión de imagen de la ciudad).

\section{Condiciones de acumulación capitalista en el Área del Gran Rosario (2003-2008)}

La estrategia de desarrollo local programada en el PER adquirió un fuerte impulso en el año 2003, que marcó el inicio de un contexto económico favorable al desarrollo de los principales productos de exportación del Aglomerado Gran Rosario y al crecimiento del sector inmobiliario y terciario en la ciudad. La concreción de obras de infraestructura como la Hidrovía Paraguay-Paraná, el Puente RosarioVictoria y la reconversión de las instalaciones portuarias apuntalaron este proceso.

A partir del año 2003, un contexto macroeconómico con tipo de cambio alto, expansión económica/capitalista internacional, repunte de los precios de los principales productos de exportación de Rosario y de Argentina, y superávit fiscal y de cuenta corriente, entre otros aspectos, favoreció un proceso de desarrollo capitalista basado en la agro-exportación (Vargas Soler, 2003:98). El nuevo tipo de cambio y el posterior repunte de los precios internacionales de productos como soja, carne, trigo y sus derivados, crearon condiciones extraordinarias para la generación de excedentes financieros a partir de la producción, comercialización y especulación en torno a dichos productos.

Parte de esos excedentes se invirtieron en proyectos urbanísticos e inmobiliarios contribuyendo a la recuperación y expansión de la construcción en el periodo 2003-2007. El dinamismo en el sector se reflejó en la evolución del número de permisos, superficies nuevas, 
ampliaciones, valor agregado y metros cuadrados construidos. Según Gasquet (1992) entre enero de 2000 y diciembre 2011, se autorizaron un total de $8.119 .633 \mathrm{~m}^{2}$ para la construcción en la ciudad. Los $\mathrm{m}^{2}$ construidos se orientaron a edificios, en el rubro "multivivienda con locales" y se localizaron mayoritariamente en el área geográfica del distrito centro. Los actores más beneficiados gracias a la expansión de la construcción y de la actividad inmobiliaria fueron los empresarios e inversores (constructores, propietarios, promotores, especuladores inmobiliarios) nucleados en agencias tales como la Cámara de Empresas Inmobiliarias de Rosario -CADEIROS- y la Corporación de Empresas Inmobiliarias de Rosario-CEIR (Vargas Soler, 2010).

A su vez, se produjo un proceso de industrialización (o "reindustrialización") sustitutiva de importaciones en las ramas de actividad que habían sido las más perjudicadas por la apertura comercial de inicios de los 90 tales como bicipartes, confecciones, calzado, maquinarias, etc. (Ghilardi María et al, 2012). También se dio un importante crecimiento de establecimientos y del producto industrial en ramas como alimentos, maderas y metalmecánica siendo las organizaciones industriales de mayor tamaño las más favorecidas (Vargas Soler, 2010). Dentro de dichas organizaciones sobresalen Cargill, Dreyfus, Swift, John Deere, Costan Market S. A, Agner Raffo S. A, Frimetal S. A y agremiaciones patronales como la Sociedad Rural, la Asociación Industriales Metalúrgicos de Rosario, la Asociación Empresaria de Rosario y la Federación de Comercio e Industria.

A la recuperación de la industria se sumó la de sectores vinculados al consumo. El crecimiento del comercio minorista, del comercio de vehículos, de restaurantes y hoteles respondió en buena medida a la recuperación y expansión de los ingresos derivados de la actividad agropecuaria, de la construcción, de la industria y de algunos servicios (Vargas Soler, 2010). Estos elementos dinamizaron la actividad comercial y abrieron posibilidades de inversión y acumulación en el sector. Tal es el caso del desembarco de grandes inversiones en centros comerciales, como el Shopping "El Portal” y el Shopping "Alto Rosario", cuya apertura transformó hábitos de consumo y de compra de la población con mayor nivel adquisitivo (Ghilardi et al, 2009). 
La realización de distintos eventos académicos, culturales y empresariales asimismo permitió a la ciudad mejorar su potencial turístico y consolidarse como principal centro de consumo de la región agrícola-ganadera del sur de Santa Fe (Ghilardi et al, 2009). En este sentido, las actividades del sector Hoteles y Restaurantes crecieron exponencialmente en el período 2003-2007, coincidiendo con la recuperación de los ingresos, las actividades de carácter cultural y la expansión de la zona comercial rosarina.

La ciudad a partir de estas dinámicas económicas consolidó un perfil orientado a los servicios ${ }^{9}$ que fue apuntalado por una serie de intervenciones urbanas que implementó el gobierno local.

5. Tecnologías de gobierno. Intervenciones urbanas

A partir de la llegada de Miguel Lifschitz a la intendencia, el Municipio, a través de la Secretaría de Planeamiento, la Secretaría General y la Secretaría de Obras Públicas, impulsó una serie de intervenciones urbanas que se propusieron consolidar a Rosario como una ciudad moderna, integrada y creativa, con una completa oferta de servicios a través de tres frentes de actuación. Estos apuntaron a: 1) optimizar las condiciones de acceso y atravesamiento de la ciudad con el objeto de adecuarla al aumento en los niveles de tránsito regional que estaba recibiendo el AMR; 2) abrir la ciudad al río para mejorar el paisaje y hacerlo atractivo a las inversiones de capital inmobiliario y comercial; 3) reforzar la centralidad creativa y cultural de Rosario para promocionar y difundir nacional, regional e internacionalmente la oferta turística de la ciudad.

9 Según Figliuolo (2012), la estructura productiva de Rosario entre los años 2003 y 2009 se mantuvo constante concentrando los servicios aproximadamente el $85 \%$ del PBG, mientras que los sectores productores de bienes representaron sólo un $15 \%$. 


\subsection{Metrópolis de la Integración y la Conectividad}

El primer frente de acción se propuso optimizar las condiciones de acceso y atravesamiento de la ciudad con el objeto de adecuarla al aumento en los niveles de tránsito regional que estaba recibiendo el AMR y con miras a lograr mayor fluidez en la conexión de los barrios periféricos con el centro (programa "Gestión del sistema vial Metropolitano y de accesos a la ciudad" [PER, 1998]). Para ello la Municipalidad de Rosario implementó diversas estrategias de cooperación público-privada y público-público.

Por un lado, tomó un crédito -Préstamo No 1068/OC-AR- del Banco Interamericano de Desarrollo (BID) en el marco del Programa de Desarrollo Integral de Grandes Aglomeraciones Urbanas del Interior (GAU) para la realización de obras de acceso y remodelación de grandes avenidas. Por el otro, se avanzó sobre la articulación del sistema vial de la costa y la entrada a la ciudad articulando con el sector privado mediante compensaciones que dispuso en los convenios urbanísticos firmados con las empresas desarrolladoras del Complejo City Center, de los emprendimientos Delfines Guaraní y de Puerto Norte.

De esta forma, el proceso de reestructuración vial creo un entorno competitivo para las empresas y las actividades económicas de la ciudad al dotarla de la conectividad territorial necesaria para la circulación de habitantes, mercancías y turistas.

\subsection{Abrir la ciudad al río}

Un segundo frente de actuación se dirigió a integrar la ciudad al río para mejorar el paisaje y hacerlo atractivo a las inversiones de capital inmobiliario y comercial. La puesta en valor del frente costero implicó la concreción de una serie de proyectos urbanísticos y la instalación de diversos usos terciarios y residenciales en dicho espacio. Entre los primeros se destacan la realización de grandes obras de infraestructura como el Parque España, el Pasaje Juramento, la Estación Rosario Central, los Silos Davis y la Reconversión del sector Puerto Norte. Estas obras tuvieron un fuerte impacto en la renovación de la zona, posibilitando la apertura de nuevos locales comer- 
ciales y la diversificación de los servicios destinados a sectores con capacidad de consumo y turismo.

Con respecto a los usos residenciales que adquiriría el sector alrededor de la costa, un dato importante es que al mismo tiempo que se recuperaba y embellecía el río "se implementó un cambio en la normativa de los terrenos privados con frente hacia la costa, incrementando fuertemente la densidad al liberar la altura máxima edificable" (Kruk, 2011:37). Ello posibilitó un proceso de enorme valorización inmobiliaria y de renovación edilicia dando lugar a emprendimientos multipropósitos de gran envergadura ${ }^{10}$. Dichos propósitos incluyen la construcción de edificios habitacionales, oficinas, centros comerciales, hoteles así como infraestructura para el aprovechamiento del río Paraná. Entre ellos se destacan las Torres Dolfines Guaraní y Acualinas, el edificio residencial Embarcadero y el edificio de oficinas de alta tecnología denominado Northlink.

En cuanto a los usos terciarios en los espacios públicos ribereños la Municipalidad utilizó como herramienta privilegiada la concesión de obra pública. Con ella el Municipio se propuso: a) recuperar y/o revalorizar el espacio público; b) asegurar el mantenimiento de espacios públicos a partir de esquemas de articulación público-privada; c) lograr una mayor rentabilidad social a partir de la inversión privada generando nuevos puestos de trabajo, jerarquizando el espacio público y posicionando a Rosario como ciudad turística y receptora de eventos; d) ofrecer nuevas oportunidades para inversores (http:// www.rosario.gov.ar/sitio/arquitectura/ concesiones/de_obra1.jsp).

Del conjunto de usos terciarios que han incorporado los espacios públicos ribereños concesionados prevalecen los servicios gastronómicos con bares, también se prestan servicios de gimnasia y de eventos sociales y empresariales.

10 Al respecto, Vargas Soler afirma que "las construcciones en la altura y en los centros -comerciales y de servicios- del AGR permitieron a los inversores privados valorizar sus inmuebles, posicionarse en espacios céntricos de la ciudad y de la sociedad de Rosario, y apropiarse de rentas urbanas diferenciales tanto primarias (por construcción en la altura) como secundarias (de comercio y servicios)" (2010:101). Se observa entonces cómo el planeamiento y la obra pública generaron un incremento exponencial de la renta del suelo urbano, del que en ningún momento, hasta la elaboración del nuevo Código Urbano en el año 2008, se dispuso su recuperación para quien lo generó, el Municipio. 


\subsection{Infraestructuras creativas}

Finalmente la tercera línea de intervención en materia de políticas urbanas municipales apuntó a reforzar y crear infraestructuras culturales que consolidaran la centralidad creativa de Rosario para promocionar y difundir nacional, regional e internacionalmente la oferta turística de la ciudad. Para ello se crearon y rehabilitaron distintos espacios ubicados en el área central (entre ellos, la Ciudad de los Niños, el Teatro Municipal La Comedia, la Casa del Tango) y se reconvirtieron edificios portuarios y galpones ferroviarios en espacios culturales como el Centro de Expresiones Contemporáneas, el Centro de la Juventud y la Isla de los Inventos.

A la creación de nuevas infraestructuras culturales se sumó la preservación del patrimonio histórico rosarino a través del cual se pusieron en valor edificios públicos, templos, casas y sitios históricos, varios de ellos mediante la firma de Convenios de Esfuerzo Compartido, otra herramienta de cooperación público-privada que co-financia obras a través del otorgamiento de un subsidio creado para ese fin. Con este mecanismo se ha rehabilitado el bar El Cairo, el Savoy, el Club Español, el teatro El Círculo y la casa De Lorenzi para dar cabida al Museo de la Memoria (Plan Urbano, 2011)

Lo expuesto en los anteriores apartados ilustra las condiciones, enfoques, racionalidades y herramientas que fueron dotando a las gestiones socialistas de un hacer y un enfoque empresarial en materia urbana. Específicamente, muestra la manera en que la articulación público-privada se convirtió en el principal organizador del proceso de distribución espacial de la ciudad a través de instrumentos como el PER, los préstamos contraídos con el BID, los convenios urbanísticos y de esfuerzo compartido, y las concesiones de obra pública. Ahora bien, ¿Cuáles fueron los efectos que siguieron al patrón empresarial de gobierno asumido por las gestiones socialistas? 


\section{Efectos de fragmentación y segregación}

Además de la consolidación de una ciudad moderna, integrada y creativa, con una completa oferta de servicios, entre los principales efectos de la modalidad empresarial que asumió el gobierno urbano en Rosario encontramos, en primer lugar, la invisibilización y falta de equipamiento de las áreas carentes de valor turístico, patrimonial y comercial (desde la perspectiva del gobierno local y del sector privado) y, en segundo lugar, la segregación espacial de los sectores sociales de menores ingresos.

Con respecto al primer punto el repaso por las políticas de citymarketing y de turismo ${ }^{11}$ permitió relevar las zonas e imágenes urbanas consideradas estratégicas y, por lo tanto, visibilizadas en la promoción de la ciudad. La mayoría de ellas se localizan en el Distrito Centro y en el área costera de Rosario coincidiendo geográficamente con los espacios que más inversiones inmobiliarias, comerciales y municipales recibieron durante la última década.

Los Distritos restantes (exceptuando el Distrito Norte) aparecen en los mapas oficiales sólo como accesos a la ciudad, corredores de circulación hacia otros lugares. Su escasa relevancia estratégica en el marketing de la ciudad, se relaciona con factores como sus menores niveles de infraestructura, la presencia de asentamientos irregulares $^{12}$, la alta concentración de personas desempleadas y su asociación con zonas inseguras.

Estos factores, paradojalmente, emergieron como resultado de la configuración de Rosario en clave empresarial. Configuración que,

11 Para la indagación se relevaron los programas implementados por "Fundación Ciudad de Rosario" y el "Ente Turístico Rosario", organismos de carácter público-privado encargados de posicionar a Rosario a nivel local, nacional e internacional para el desarrollo turístico de la ciudad como también para la promoción de nuevos mercados.

12 En el año 2013, la ONG TECHO realizó un relevamiento de asentamientos informales en varias provincias y regiones del país entre las que se encontró el Gran Rosario. Según el informe final que publicó la organización, existen actualmente en Rosario 110 asentamientos informales en los que se alojan aproximadamente 35.610 familias. El rastreo geográfico de los mismos permitió observar que los asentamientos se encuentran rodeando el área central y costera de la ciudad, siendo el Distrito Oeste el que mayor porcentaje de asentamientos posee, con el 32.7\%. A éste le suceden el Distrito Sudoeste con el 25.2\%, el Distrito Norte con el 14.9\%, el Distrito Sur con el 13\%, el Distrito Noroeste con el $12 \%$ y el Distrito Centro con el $1.8 \%$. 
articulada alrededor de la lógica de acumulación y beneficio de las empresas, imposibilitó mejoras en las condiciones de trabajo del sector que más empleo absorbió -el sector terciario- ${ }^{13}$ y profundizó el proceso de expoliación urbana ${ }^{14}$ al que se encontraron expuestos las franjas de menores ingresos.

Un indicador de este último pudo hallarse en el crecimiento del número de asentamientos irregulares en la ciudad. Si en 1996 existían 91 asentamientos informales con alrededor de 22.685 familias viviendo en ellos (Fundación Banco Municipal, 1996), en 2013 el número ascendió a 110 asentamientos y 35.610 familias (Techo, 2013). Entre las causas de este aumento se encontró el funcionamiento del mercado inmobiliario rosarino, orientado a la oferta de viviendas como refugio de valor ${ }^{15}$, y la inversión municipal en el equipamiento urbano de las zonas más valorizadas para el capital privado.

La concentración de las imágenes, de la calidad de los servicios básicos y de infraestructura habitacional en el Distrito Centro responde a un modelo empresarial de gestión urbana que ha apostado a mejorar la posición competitiva de la ciudad con respecto a la división espacial del consumo. Se trata de atraer consumidores con dinero, mediante la promoción del turismo y las inversiones centradas en mejorar la calidad de vida y de los servicios en las zonas más valoradas de la ciudad. Las inversiones se concretan en áreas que van desde la innovación cultural y mejora física del entorno urbano, hasta inversiones en atracciones (estadios deportivos, centros comerciales y de convenciones, restaurantes exóticos) y ocio (espectáculos urbanos,

13 A pesar del dinamismo que adquirió la economía de servicios en la postconvertibilidad, su desarrollo no posibilitó mejoras significativas en las condiciones de trabajo en dicho subsistema, ya que si bien disminuyeron las tasas de sub-empleo en la ciudad, los salarios no registraron un crecimiento sustantivo, no hubo progresión en la distribución de los ingresos y se presentaron retrocesos en aspectos como la cobertura en salud de la población empleada y las tasas de sobre-ocupación (Vargas Soler, 2010).

14 Según Soldano (2008), la expoliación urbana es resultado de diversos procesos, a saber; las privatizaciones, el aumento de los precios de los servicios públicos, la recesión económica y el aumento de la desocupación, el deterioro de la infraestructura urbana y habitacional resultado de la desinversión pública y la fragmentación socio-territorial traducida en la generación de áreas con gran calidad de servicios e infraestructuras urbanas frente a otras de provisión deterioradas.

15 Según el Colectivo de Investigaciones Urbanas (2012) de un total de 435 mil viviendas, 80 mil se encuentran deshabitadas cumpliendo el rol de refugio de valor sojero y de otros mercados como el financiero y los negocios ilegales. 
festivales y acontecimientos culturales) implementadas con el presupuesto municipal y con herramientas como convenios público-privados y concesiones de obra pública, analizadas en el capítulo anterior.

Ante la configuración de Rosario en torno al consumo cabe preguntarse cómo se resuelve el acceso a la ciudad frente a la ausencia de capacidad de pago, en sociedades fuertemente patrimonialistas y en las cuales se ha generalizado el principio liberal de responsabilidad individual de acceso a la tierra, a la vivienda y a la cultura. La discusión por el derecho a la ciudad implica necesariamente repensar el lugar del Estado ya que mediante sus diversos programas, desde el planeamiento urbano, la regulación económica, la política fiscal y la inversión infraestructural hasta la provisión diferenciada espacialmente de bienes y servicios públicos como la vivienda, la educación, la salud y la policía establece la amplitud de la distancia entre la cumbre y la base del orden urbano; los vehículos, caminos, y la facilidad con que se puede cruzar esa distancia; y qué formas de exclusión socioespacial echan raíces y crecen (Wacquant, 2012).

\section{Conclusiones}

A lo largo del trabajo se intentó desarrollar la modalidad empresarial de gobierno urbano que adoptaron las gestiones socialistas a partir de 1995 en la ciudad de Rosario. Para llevar adelante esa tarea, la perspectiva teórica asumida orientó la indagación hacia las condiciones que hicieron posible la emergencia de la gobernanza urbana empresarial en Rosario, en particular las racionalidades políticas y las tecnologías de gobierno mediante las cuales se desplegó en esta última.

Con respecto a la primera dimensión se encontró que fue necesario en primera instancia garantizar la gobernabilidad urbana. La estrategia escogida para ello fue la reforma del aparato administrativo Municipal mediante el Programa de Descentralización y Modernización de la Municipalidad de Rosario y luego el Presupuesto Participativo Rosario. Estos programas se presentaron como vía de 
restauración de la confianza hacia las instituciones políticas y funcionaron como poderosas herramientas de neutralización del conflicto social. Favorecieron, de esta forma, la estabilidad necesaria para alcanzar las metas que la orientación empresarial de gobierno había asignado a la ciudad: el logro de la competitividad y productividad del sistema económico territorial rosarino.

Con respecto a la segunda dimensión, se identificó al Desarrollo Local y a la Planificación Estratégica como los principales enfoques que estructuraron el campo discursivo sobre el que se desplegó el empresarialismo urbano en la ciudad. En el nuevo enfoque de gobierno las empresas fueron concebidas como el verdadero motor del desarrollo económico y los Municipios debían adoptar respecto de éstas un rol inductor, promotor, más que el mero rol regulador de antaño. El supuesto sobre el que se asentaron estos postulados sostuvo que la combinación de recursos privados con capacidades gubernamentales atraería financiamiento externo, inversión directa y nuevas fuentes de empleo, propiciando financiación alternativa a los Municipios carentes de recursos.

Paulatinamente el Estado local se configuró como facilitador de las acciones privadas y la concertación de estos dos sectores se convirtió en el mecanismo central de planificación del desarrollo urbano y económico de la ciudad. Sus vínculos dieron lugar a herramientas como el PER, concesiones de obra pública, convenios urbanísticos y las intervenciones urbanas analizadas, que aumentaron el poder de incidencia del empresariado en el gobierno urbano local.

Rosario efectivamente se convirtió en centro geopolítico y económico de una amplia región metropolitana y central, y en una ciudad moderna, integrada y creativa. No obstante, el equipamiento del espacio urbano no fue homogéneo para toda la ciudad, sino que privilegió las zonas con mayor atractivo inmobiliario, turístico y de servicios.

A modo de reflexión final, de cara a la naturalidad con que aparecen las desigualdades producidas por el modo empresarial de gobierno urbano, el presente trabajo sostiene la necesidad de reivindicar el carácter social de la producción de la ciudad y, en ese sentido, el 
derecho colectivo de todos/as aquellos/as cuya labor está dedicada a producirla y reproducirla, no sólo a disponer de lo que producen, sino también a decidir qué tipo de urbanismo se debe crear, dónde y cómo.

Desandar los mecanismos y actores mediante los cuales se conforma actualmente el espacio urbano, analizar la modalidad que asume la apropiación diferencial de la ciudad y estudiar los discursos y las racionalidades políticas que la sostienen, constituye el primer paso para imaginar formas alternativas de construir lo urbano. Crítica de lo que ya hemos devenido (Sacchi, 2010) para resistir, sin resignarse a este injusto orden de cosas.

\section{Referencias bibliográficas}

BIFARELLO, M. "Una ciudad participativa y eficaz. Derecho a un Estado Municipal transparente y cercano a la gente" en Politicas para la gobernabilidad, Rosario, 2005 [en línea 20/10/2014]. Disponible en internet: http://www. rosario.gov.ar/mr/mri/www/ premios/experiencia-rosario-politicas-para-la-gobernabilidad.

CAMPANA, M. Medicalizar la asistencia. Asistencializar la salud. Rosario, Prohistoria ediciones, 2012.

CATENAZZI, A. y RESSE, E. La construcción de estrategias de desarrollo local en las ciudades argentinas. Buenos Aires, Mimeo, 2000.

CLICHEVSKY, N. Política social urbana. Normativa y configuración de la ciudad. Buenos Aires, Espacio Editorial, 1996.

CUENYA, B. "Globalización y políticas urbanas. Transformaciones de las políticas urbanas en la ciudad de Buenos Aires", en: Revista Sociológica, año 15, número 42, México, pp. 35-37, 2000.

CUENYA, B. y CORRAL, M. "Empresarialismo, economía del suelo y grandes proyectos urbanos: el modelo de Puerto Madero en Buenos Aires" en: EURE, Vol 37, N 111, Pontificia Universidad Católica de Chile, pp. 25-45, 2011.

DE MATTOS, C. "Modernización capitalista y transformación metropolitana en América Latina: cinco tendencias constitutivas" en: GERAIGES de LEMOS, A. I., ARROYO M., SILVEIRA M.L. América Latina, cidade, campo e turismo. San Pablo, CLACSO, 2006. Pp 41-73.

DE MARINIS, P. “Gobierno, gubernamentalidad, Foucault y los anglofoucaultianos (O: un ensayo sobre la racionalidad política del neoliberalismo)" en: GARCÍA SELGAS, F. y RAMOS TORRE, P. Globalización, riesgo, reflexividad. Tres temas de la teoría social contemporánea. Madrid: Centro de Investigaciones Sociológicas, 1999. Pp. 73-103. 
Gasquet, R. (coord.) Asentamientos irregulares en la Ciudad de Rosario. Características físicas y urbanísticas. Indicadores Sociales. Rosario, Fundación Banco Municipal de Rosario. Grupo de estudio Asentamientos irregulares de Rosario, 1992.

FERNÁNDEZ, A. et al. Posicionamiento, competitividad e imagen de la ciudad de Rosario, Rosario, 1997 [En línea 20/10/2014]. Disponible en internet: http://www. catedranaranja.com.ar/taller2/notas_T2/Posicionamiento_Ciudad_Rosario. pdf. -

GARCÍA DELGADO, D. "Nuevos escenarios locales. El cambio en el modelo de gestión" en VENESIA, J- compilador- Políticas públicas y desarrollo local, FLACSO- CEI(UNR)- IDR, Rosario, 1998.

GHILARDI, M. et al. "El sector comercio en la región Rosario: Evolución del Producto y el Empleo en la postdevaluación", ponencia presentada en las Decimocuartas Jornadas "Investigaciones en la Facultad" de Ciencias Económicas y Estadísticas, UNR, 9 al 11 de Noviembre, 2009.

HARVEY, D. El nuevo imperialismo. Madrid, Ediciones Akal, 2007.

KRUK, L. "Recuperación del espacio público en la ciudad de Rosario, Argentina" en: Revista eletronica de arquitetura eurbanismo, Vol Nº 6, pp. 30-45, San Pablo, Universidade Sao Judas Tadeu Brasil, 2011.

LIFSCHITZ, R. "Planificación y estrategia: el caso del PER” en: VENESIA, Jcompilador- Políticas públicas y desarrollo local, Rosario, FLACSO- CEI- (UNR)- IDR 1998.Pp. 161-172.

OCDE ESTUDIOS TERRITORIALES. "Ciudades competitivas: Un nuevo paradigma empresarial en desarrollo espacial. Resumen en español”, 2007 [En línea: 20/10/2014]. Disponible en internet: http://www.centroscomunitariosdeaprendizaje .org.mx/ sites/default/files/Ciudades\%20competitivas\%20Un\%20nuevo\%20paradigma $\% 20$ empresarial\%20en\%20desarrollo\%20e spacial.pdf.

MUNICIPALIDAD DE ROSARIO. Plan Estratégico Rosario, Rosario, 1998 [En línea 28/10/2014]. Disponible en: http://www.perm.org.ar/per98/per_98.pdf.

SOLDANO, D. "Vivir en territorios desmembrados. Un estudio Sobre la fragmentación socio-espacial y las políticas sociales en el área metropolitana de Buenos Aires (19902005)" en ZICCARDI, A. -compiladora- Procesos de urbanización de la pobreza y nuevas formas de exclusión social. CLACSO-CROP Series, Siglo del Hombre Ediciones, Bogotá. Pp. 37-69.

THEODORE, N., PECK J. y BRENNER N. (2009): "Urbanismo neoliberal: la ciudad y el imperio de los mercados", en: Revista Temas Sociales, V. 66, Santiago de Chile, Ediciones Sur, 2009.

VARGAS SOLER, J.C. Re-estructuración económica y desarrollo local en el Gran Rosario: una mirada desde la perspectiva latinoamericana de la economía social, Buenos Aires, 2010 [En línea 20/10/2014]. Disponible en: http://www.ungs.edu.ar/ms_ ungs/ wp-content/uplo ads/2012/03/VARGAS-TesisMAES.pdf.

Recepción: 15/05/2015

Aceptación: 22/09/2015 